\title{
The Influence of Education and Scientific Research System on China's Science and Technology Innovation Capability
}

\author{
Guo Hongfei ${ }^{1,2}$, Gong Pei ${ }^{3}$, Zhang $\mathrm{Ru}^{1,5}$, Fang Jiaxin ${ }^{5}$, He Zhihui ${ }^{4}$, Qu Ting ${ }^{1,2}$, Li Congdong ${ }^{1,2}$, Huang Guoquan ${ }^{1,2}$ \\ ${ }^{1}$ Institute of Physical Internet, Jinan University, Zhuhai, China \\ ${ }^{2}$ Institute of intelligent science and engineering, Jinan University, Zhuhai, China \\ ${ }^{3}$ School of materials, Inner Mongolia University of Technology, Hohhot, China \\ ${ }^{4}$ Institute of Metrology and Physics, Inner Mongolia North Heavy Industries Group, Baotou, China \\ ${ }_{5}^{5}$ Finance Department of International Business School, Jinan University, Zhuhai, Guangdong Province, China \\ Correspondence: Pei Gong, School of materials, Inner Mongolia University of Technology, Aimin Road 49\#, Hohhot \\ City, Mongolia Province, Post No. 010051, China.
}

Received: August 6, 2018

doi:10.11114/ijce.v1i2.3642
Accepted: September 18, 2018

Online Published: September 19, 2018

\begin{abstract}
This article outlines their impact on China's technological innovation capabilities from nine aspects including primary and secondary education to university education, the shortcomings of scientific research evaluation system, the forward-looking of educational investment and the rationality of research funding, the negative feedback of the employment market on innovative research, intellectual property protection and incentive mechanism, The basic social system and its incentive mechanism combined with learning and research, the incentive mechanism and cultural atmosphere of enterprises and administrative institutions, and the origin of China's modern education model. The comprehensive analysis shows that changing the status quo of China's lack of innovation is a systematic project. A single ministry cannot complete many specific measures of reform, and must have a national-level top-level design. Through reform, the education and scientific research system has reasonable design and strong self-repairing ability. It is the need of innovation to promote industrial upgrading. Its effectiveness directly determines whether China can cross the middle income trap and the great rejuvenation of the Chinese nation.
\end{abstract}

Keywords: educational model, scientific research management, innovation ability, middle income trap

After observing the effect of teaching practice based on the teaching system of the former Soviet Union since the liberation of 1949, it is not difficult to draw conclusions about the lack of innovation. Especially in the past 20 years, with the close proximity to the software and hardware conditions of developed economies, we have become more aware of the gap in innovation capability. China's entire education system and relevant evaluation and management system should be self-examined and reflected. It is necessary to re-evaluate the systems including the teaching system, the scientific research evaluation system, financial investment policy and preferences, intellectual property protection and incentive mechanism, and the basic social system involving the combination of production, learning and research and its incentive mechanism. In fact, there are problems in the education system throughout Asia, and it is characterized by extreme examination-oriented and academic doctrinaire (Wang, 2007).

\section{Problems in the Teaching System of Primary Schools, Middle Schools and Universities}

The influence of the education system of primary schools, middle schools and universities on the ability of scientific and technological innovation is the most far-reaching and most influential factor, involving all aspects of teaching methods and teaching evaluation guidance incentive mechanism. For example, the guiding direction of the college entrance examination, the ability evaluating methods of the college entrance examination, the degree of freedom of professional choice, and the way teachers teach. The reform of the college entrance examination has been steadily advanced. However, the reform of teaching methods cannot be changed to the innovative and interactive teaching methods that guide students to think independently due to the fierce competition in the college entrance examination.

An article entitled "One Class 'Classic' Teaching Course" by Wang Hongjia in China's New Education Storm published by Beijing Publishing House describes a teaching class with Chinese characteristics observed by an English and 
American education expert in a middle school in Beijing. The teachers are calm, fluent, and well-organized. The students actively answer questions, and the answers are quite level. The whole class is impeccable. But after the meeting, foreign experts raised the question: the students answered very well, it seems that the students can master it, so why should they attend this class? They believe that the perfect and impeccable speech of the top teachers replaces the students' exploration process, and they lose the opportunity to develop their learning ability. This is a teacher's performance class, and the students are only watching the teacher perform (Wang, 2007).

In the Southern Metropolis Daily on December 20, 2004, Xue Yong's "Crisis of Declining Reading Rate" pointed out the shortcomings of the current cramming education in primary schools, middle schools and universities from the perspective of reading. The reading feature is able to reflect the subjectivity of the recipient, the speed can be adjusted by readers, some content can be repeatedly pondered and questioned, and the process of receiving information is always accompanied by thinking, while the speed of TV and cramming education is fixed, the receiver is in a passive state and lacks space for thought (Xue, 2004).

Therefore, the reform of teaching methods is especially needed in middle schools. However, in order to cope with the college entrance examinations whose questions are impractical, wide in range and large in numbers, there is no time for open interactive teaching. It is necessary to hurry and inculcate the questions into the students' minds in order to increase the rate of school attendance associated with teacher and school income.

Schools often publish their children's exam rankings, which has led to "senior rankings" being a sensitive topic. In the United States, grades are personal privacy, not a tool for children or parents to compare and humiliate each other. The priority is to learn something and remember the mistakes made, but not letting your child care too much for one or two points of the exam! After all, entering the society, who cares about your ranking in primary school or the awards you have won?

Many valuable contributions (literatures, works of art, and scientific and technological achievements) in the history of mankind were completed by the parties before their 20s. If pupil, middle school students, undergraduates, and graduate students have always focused their energies on reciting theories and formulas, and striving for rankings, they will miss the golden age of 20 . This is the main reason why there is no big innovation after the liberation of China (the previous imperial examination was also busy with examinations and few results).

As the guide sign of China's comprehensive and long-term top-level designed education, the college entrance examination is also in urgent need of reform.

In addition, China's higher education is divided into different majors along with the former Soviet Union. After 1998, although the amalgamation reduces the number of majors, the content and integration of teaching and practical training have not changed much. Although some colleges have set up comprehensive experiments, neither the credit hours nor the comprehensive practicality can compare with the specialized education in developed countries. Take a Canadian electronic school for example, they have theory class in the morning and afternoon in laboratory experiments, each step of experiment needs the signature of teacher after the completion, until the experiment is complete. Usually, these experiments account for 90 points, and the final exam takes 10 points. Because the daily courses and experiments are carried out around the complete production of a specific complex product, such as copiers, it will involve not only the welding of circuits, the preparation of simple programs, but also the communication between equipment and the host, etc. It involved in the professional equivalent of domestic electrical engineering, electronic technology, communication technology, control principles and technology, and computer programming. In this area, China has are no textbooks or schools! How can the country's technological innovation capability improve without teacher with comprehensive knowledge and skills, schools and textbooks? We need to aware that almost all innovative products are multidisciplinary fusion and penetration in the era of knowledge explosion.

\section{Problems Existing in the System of Scientific Research and Innovation}

\subsection{Problems in the Scientific Evaluation Systems}

On December 19, 2010, the economist Zhu Xiqing pointed out in the Southern Metropolis Daily that the university has dried up as a source of new knowledge because of the current research evaluation system based on the papers' level and citation factors from the United States.

Universities in the United States originally used peer evaluations. After the Vietnam War, young people in the university questioned the authority, and begin to compare the number of articles published and the influence factors, disrupting the periodicity of knowledge production. An original research usually causes decade to complete, but without recent-published articles, stuffs have to leave in current day. For example, a doctor takes seven years desperately publish articles trying to get promotion, this kind of eager for quick success and instant benefits makes the United States herself encounter knowledge exhaustion problem. Her achievements in computers and bio-pharmaceuticals at the end of 
the last century were mainly derived from the theoretical foundations before the 1960s.

Zhu xiqing believes that a reasonable and scientific research evaluation system is based on the university management system, which contains three key points. The first is peer evaluation. Pursuing quick success in articles publishes and rejecting long-term original researches should be avoided. The second point is that professors should run schools. De-administrating is necessary because professors are the core of universities. The third point is academic independence. The old professors did well in the university and held high positions, but after the new knowledge came into being, the old knowledge was devalued. To avoid the decline of status, some professors may try to kill the new knowledge. Without academic independence, the generation of new knowledge will be rejected. Therefore, universities must be academically independent and cannot be controlled by others (Zhu, 2010).

\subsection{Prospectiveness of Education Investment and Rationality of Research Funding Allocation}

Without the financial foundation and policy supporting education and scientific research, scientific and technological innovation is like water without a source, or a tree without roots. After the Second World War, United States spent nearly 200 years to accumulate wealth and gather elites and after massive capitalization of national income, the surplus capital was invested in universities, resulting in its most competitive education system. Therefore, the state should actively strengthen investment in universities on the basis of reform of the basic system and guide the preference of knowledge investment for social surplus savings (Zhang\& Huang, 2006). China is currently in the window of industrial upgrading and structural transformation. In the long-term view of the whole society, huge amount of domestic savings should be invested on universities and other invention-creation activities that produce new knowledge for it accords the most with the long-term interests of social development and has the highest rate of return. Compared with real estate and large infrastructure, this is the only effective investment way.

China's scientific research funding can be divided into three levels in the aspect of source. The national level mainly includes the science and technology system based on the National Natural Science Foundation of China and other breaking frontier projects like the 863,973 . Provincial scientific research mainly comes from provincial science and technology departments. In addition, there are also self-financing funds of enterprises and institutions (Zhou, 2013). Take the National Natural Science Foundation of China as an example. Its advantages over the years have been remarkable. In this article mainly discusses its shortcomings in the allocation, usage and acceptance of funds.

In terms of distribution, due to the use of a fixed judging panel composed of well-known scholars and experts, plus each small direction has a limited circle, the actual implementation result is that the people who have a high probability of obtaining the subject are mainly disciples and friends of the circle members. Another irrationality of distribution is reflected in the increasing quota, and the general program has reached more than 800,000 yuan. This allocation is obviously inferior to decomposing into four 200,000 yuan. By increasing the coverage, people who cannot meet mechanical application conditions but with innovative abilities will have the opportunities to develop their talents. The history of human development in the past 200 years has also proved that most great innovations are done by unknown young people under the age of 27.

The flaws in the use of funds are mainly manifested in the fact that because the members of the circle are older, most of them hold leadership positions. However their knowledge structure is inevitably lagging behind and they lack innovative and adventurous spirit. The project is then carried out around the personnel and research direction recognized by the circle members. Plus, the specific scientific research is mainly completed by doctors and masters without interdisciplinary experience and knowledge. It eventually presents innovation deficiency of core science and technology leading the frontier in China in the past 30 years, especially the product innovation involving interdisciplinary comprehensive application!

The drawbacks of capital acceptance are mainly reflected in the eager for quick success and instant benefit. Most scientific research requires a long accumulation and experiment. Therefore, scientific research acceptance should not limit fixed number of years. When the project undertaker obtains valuable or breakthrough results, he can voluntarily apply for the conclusion or continue to apply for follow-up funds, and the executive committee will evaluate its potential and the value of the outcome to decide whether to continue funding. If the coverage rate of $25 \%(800,000)$ is extended to $100 \%$ coverage $(200,000)$, not only can eliminate corruption and waste of funds, but also can guide all researchers to concentrate on researches and innovations, rather than to post articles for the purpose of concluding the researches.

\section{The Impact of Employment and Incentive Mechanism on Scientific and Technological Innovation}

Although interest is the best teacher, good and fair employment opportunities and stable income expectations are the basic conditions for achieving technological innovation.

The 2010 Michaels Research Employment Survey shows that 30\% of students are assigned to their job through relatives, 
friends and acquaintances, while $70 \%$ of freshmen leave within one year, which means that $30 \%$ of students who get jobs through relationships can meet basic job expectations. (Peng, 2003). The unspoken rule of employment is that the unprofessional managerial and technical posts in state-owned enterprises or large private enterprises are mostly occupied by the related parties. This unfair phenomenon has been reduced with the implementation of the public examination system of administrative institutions, but still exists in enterprises. The public examination content of administrative institutions has little to do with the knowledge of professional science and engineering; the employment opportunities and expected income of students facing enterprises have little relation with the mastery and application level of scientific knowledge, which causes the phenomenon of non-ideal academic atmosphere in colleges and universities. All these factors influence China's scientific and technological innovation ability imperceptibly (Wang, Sun \& Hao, 2009).

The low income and status of scientific researchers lead to the flow of elites to abroad and civil servants within the system. The unfair distribution of scientific resources leads to the flow of elites to scientific research institutes and the official sites of universities. Therefore, the scientific research field should also advocate the "no official power should pursue wealth and no wealth could be pursued through official power" rule proposed by President Xi, here the rule can be changed to "no administrator should conduct scientific research and no scientific research should conduct by school administrator". Even though the administrator does not have the energy to conduct scientific researches, they use power to occupy a large number of scientific research resources, making the teachers and researchers with ambition and ability lack the basic conditions and funds for scientific research. The flow of a large number of elites to the officialdom makes the system reform more difficult.

\subsection{Intellectual Property Protection and Incentive Mechanism}

From the perspective of knowledge flow, the 30 years of China's reform and opening up are mainly 30 years of knowledge inflow, imitation and integration innovation. With the close proximity of the total knowledge to developed economies, problem such as raw materials, energy, and environment and labor costs emerges in primary processing, lead to overcapacity, simple imitation and even the lack of integration innovation. In order to avoid "middle class trap" industry influencing the upgrading and transformation of other industries, it is urgent to strengthen the protection of intellectual property rights from the whole society, so as to form a virtuous cycle for social capital to invest in the knowledge assets obtained from universities. For example, at present, $30 \%$ of the workers in the United States belong to the "creation class". They have high level of freedom. In the job market, they are not looking for a job, but are chased by enterprises. Any "whimsical" enterprise without them will lack vitality. .

\subsection{Basic Social Systems and Incentive Mechanisms Related to the Combination of Production, Learning and Research}

In recent years, the investment in scientific research funds in China has increased year by year, but the actual results have not been positively improved. Part of the reason is that the poor combination of production, education and research. The most common applications for colleges and universities are the National Natural Science Foundation. These fund topics mainly collect from the recommendations of mainstream scholars, not from the practical problems of the first line of production research. China's production, learning, and research are basically in a state of separation (Pan\& Liu, 2006) (Li, 2013).

The author finds that colleges and universities have been engaged in theoretical teaching for a long time, and have mastered comprehensive and up-to-date knowledge, but they do not understand the specific conditions of latest production. Scientific research institute is like a fan of stars, which will follow whatever new subjects currently have. However, even enterprises with a large scale have no thorough large-scale research institution, or even if there is, there is no labor mechanism for the free flow and exchange of talents with universities or long-term effective cooperation mechanism. Therefore, the cooperation mechanism of "production, study and research" must be established correctly and we must establish a long-term and reasonable operating system from the three aspects of personnel, capital, and reward.

\subsection{Incentive Mechanism and Cultural Atmosphere of Enterprises and Administrative Institutions}

The personnel appointment mechanism of enterprises and administrative institutions, especially the personnel appointments of large enterprise groups and departmental level (including the future departmental level) is still decided by the organization department. The organization department understands neither the business characteristics of each person on the scene, nor the development trend of each industry, which inevitably leads to the administrativeization of academic research. The final result is the layman's leadership, the politicians' leading scholars. This leads to the politicization of middle-level cadres, with limited research resources and funds concentrated in the middle and high-level, marginalized scholars who are interested, have time and have the energy to concentrate on their research and research. Therefore, even if all you want is to well conduct the scientific research, you must first compete for the position of administration, so that the atmosphere of universities and research institutes is not pure and people are not concentrating. 
When the research institute appoints official positions and allocates resources (research funds and equipment funds), it should adopt the point system, through the work and achievements completed over the years, plus peer review (not within department, but the peers outside the department, the democratic evaluation within department can work as a supplement) to queue, using the method of declining the allocation of funds according to the ranks, it is similar to the upgrade mechanism in the games, that is, when experience value to upgrade standards, one will naturally upgrade.

\section{Countermeasures and Prospects}

The imperial examination system that based on the private school has been practiced in China for nearly a thousand years. The basic education system introduced in the modern era is characterized by the standardized curriculum that artificially cuts the human thought field into pieces. It is derived from Prussia and then introduced to the United States. The students trained in this education system are characterized by easy management and professionalism. Its main historical role is to serve the manufacture of products in the pre- and post-industrial era. At present, China urgently needs innovative talents. Obviously, the old education system needs timely adjustment or even fundamental reform. However, the basic characteristics of talents in demand are self-guided lifelong learners who have strong reading ability and plasticity, profound mathematical literacy and humanistic knowledge and curiosity and creativity (Liu\& Jiang, 2012).

What is the purpose of education? Is it to achieve employment? Or is it to educate the people and unify the thinking so as to achieve stability and order? Is it to learn specific engineering techniques? Or, as in the past dynasties of China, for the political career which means the so-called "a good scholar can become an official"? This issue is the core issue of education, and the system design around all aspects of education cannot avoid this core issue. From the perspective of the state, it is understandable to make the education system of each historical period serve the national interests, or even trying to achieve quick success. However, it is necessary to preserve the traditional humanities education that has been moral foundation for thousands of years. From the current ideological and moral decline of the social elites and the lack of integrity of the commercial class can show its importance. Not long ago, Qian Wenzhong proposed in the "New Oriental Family Education Summit Forum" that education, especially basic education, shouldn't just develop completely with the development trend of society maybe. He also questions: whether the society is educating education or the society? He advocates the implementation of certain disciplinary education and believes that learning is painful for most children. Otherwise, there would be many masters.

On this issue, Yale University President Schmid Gaudet have said, "As for education, the earliest proponents of social services, I would say, we must not forget that the University College of Education is not for job, but to life ". he said, the university should "adhere to the curiosity of young people must be civilized people to accept the knowledge, no need to answer whether it is useful for public utilities, it is realistic, whether they have social value such as" On the contrary university education would be deviation from the "right knowledge, loyalty ".

Education is a "human education". It is a social activity aimed at developing people's minds, cultivating people's independent thinking ability, learning ability and collaboration ability. It must teach students in accordance with their aptitude and have different specific rules at different stages of education, while some basic humanistic ideas should be stable and form the ideological basis for the recognition of all social classes, so as to stabilize the continuation and prosperity of society.

In a word, the reasons for insufficient innovation ability in China are reflected in all aspects of the teaching and scientific research. To change this situation is a systematic project. Single ministry is limited to complete many specific measures of reform, so a national-level top-level design is necessary. Including the teaching system, research evaluation system, financial investment policy and preferences, it should be completed the design and program form the perspective of primary and secondary schools and university teaching system, scientific research evaluation system, the financial investment policy and preference, the protection of intellectual property rights and incentive mechanism and the social basic system and incentive mechanism involving the production, study and research. If not having this work done, it will be like adopting sporadic and piecemeal steps as the physician who treats the head when only the head aches, and treat the foot when only the foot hurts, no matter how huge the amount of money has been invested, it will not improve the ability to innovate entirely.

The education and scientific research system has reasonable design and strong self-repairing ability, which can make China's education and scientific research system more reasonable and more efficient, therefore competent to complete the historical task of promoting industrial upgrading through innovation, and the effect of industrial upgrading directly decide whether China can get pass the middle class trap and realize the great rejuvenation of the Chinese nation! 


\section{References}

Li, Y. L. (2013). Problems and Countermeasures of College Students' Science and Technology Innovation Education. Journal of China University of Petroleum: Social Science Edition, 29(6), 101-104.

Liu, R. F., \& Jiang, G. Q. (2012). Build a "four-oriented" framework system to implement science and technology innovation education. Tianjin Education, (3), 44-45.

Pan, L., \& Liu, Y. F. (2006). The role of research universities in innovative countries. Science and Technology Management Research, 26(8), 6-7.

Peng, J. S. (2003). Innovative education and the cultivation of students' non-intellectual factors. China Higher Education Research, (5), 81-82.

Wang, H. J. (2007). A “classic” teaching class. Youth Expo, (7), 54-54.

Wang, Y., Sun, Z. J., \& Hao, C. J. (2009). Research on the establishment of science and technology innovation education platform for college students. Journal of Dalian University, 30(3), 36-38.

Xue, Y. (2004). The crisis of reading rate decline. Southern Metropolis Daily. December 20, 2004.

Zhang, L. P., \& Huang, Y. X. (2006). Research-based university education technology innovation ability system structure and innovation strategy. Science and Technology Progress and Countermeasures, 23(5), 151-153.

Zhou, P. (2013). Reflections on the status quo of education and science and technology innovation in China. Science and Technology Vision, (36), 151-151. .https://doi.org/ 10.19694/j.cnki.issn2095-2457.2013.36.118

Zhu, X. Q. (2010). The source of knowledge on China's follow-up development. Southern Metropolis Daily [N]. December 19, 2010.

\section{Copyrights}

Copyright for this article is retained by the author(s), with first publication rights granted to the journal.

This is an open-access article distributed under the terms and conditions of the Creative Commons Attribution license which permits unrestricted use, distribution, and reproduction in any medium, provided the original work is properly cited. 